\title{
Unveiling the role of ancillary ligands in acceptorless benzyl alcohol dehydrogenation and etherification mediated by mesoionic carbene iridium complexes
}

\author{
Angela Vivancos, ${ }^{\mathrm{a}, \mathrm{b}}$ Ana Petronilho, ${ }^{\mathrm{b}}$ Joao Cardoso, ${ }^{\mathrm{b}}$ Helge Müller-Bunz ${ }^{\mathrm{b}}$ and \\ Martin Albrecht*,a,b
}

a Departement für Chemie und Biochemie, Universität Bern, Freiestrasse 3, CH-3012 Bern, Switzerland.

b School of Chemistry \& Chemical Biology, University College Dublin, Belfield, Dublin 4, Ireland.

E-mail: martin.albrecht@dcb.unibe.ch

\begin{abstract}
We synthesized a set of triazolylidene iridium(III) complexes $\left[\operatorname{IrCp} *\left(\mathrm{C}^{\wedge} \mathrm{N}\right) \mathrm{L}\right]^{\mathrm{n}+}\left(\mathrm{Cp}^{*}=\right.$ pentamethylcyclopentadienyl, $\mathrm{C}^{\wedge} \mathrm{N}=\mathrm{C}, \mathrm{N}$-bidentate coordinating pyridyl-triazolylidene) containing different neutral or anionic ancillary ligands $\mathrm{L}$ and evaluated their impact on the catalytic activity in alcohol conversion. We demonstrate that these ancillary ligands have a strong influence on the catalytic selectivity and direct whether the iridium center preferentially catalyzes either the dehydrogenation or the dehydration of benzyl alcohol. Ligand exchange experiments provide a direct correlation of ligand lability with catalytic activity and selectivity. These results underline the relevance of ancillary ligands and provide a rational approach to tailor the catalytic activity of the iridium center towards aldehyde formation (loss of $\mathrm{H}_{2}$ ) or etherification (elimination of $\mathrm{H}_{2} \mathrm{O}$ ).
\end{abstract}






\section{Introduction}

In contrast to reductive transformations such as (transfer) hydrogenations, which are mechanistically very well understood, comparably little is known about oxidative catalysis. ${ }^{1}$ This lack of understanding may be, in parts, due to the oxidation sensitivity of many privileged ligand classes such as phosphines. With the emergence of N-heterocyclic carbenes ${ }^{2}$ as powerful ligands, ${ }^{3}$ a class of strong donors has become available that is generally inert to oxidative degradation. ${ }^{4}$ Consequently, a range of transition metal complexes containing N-heterocyclic carbenes have been demonstrated to have remarkable activity as catalysts for oxidation reactions, ${ }^{5}$ such as the dehydrogenation of alcohols to yield ketones or aldehydes. ${ }^{6}$ This reaction usually requires the use of a base to facilitate $\mathrm{H}^{+}$displacement, and generally yields the corresponding carbonyl derivatives selectively. In the absence of a base, this process is often slow and requires high catalyst loading. ${ }^{6}$ Similar transformations have been investigated with amines. ${ }^{7}$ With specific complexes, dehydration reactions of alcohols display altered selectivity and afforded ethers from the coupling of two equivalents of alcohol and elimination of $\mathrm{H}_{2} \mathrm{O}$ (dehydration pathway) as opposed to dehydrogenation. ${ }^{8}$

We have recently reported an iridium complex containing a $C, C$-bidentate chelating triazolylidene-pyridylidene ligand that mediates both the dehydrogenation and dehydration of alcohols without the use of an external base ${ }^{8 \mathrm{~b}} \mathrm{With}$ a $\mathrm{C}, \mathrm{N}$-bidentate triazolylidene-pyridyl ligand, the addition of silanes affects the process and enhances the selectivity towards the formation of ether products from a variety of ketones, and also from alcohols. ${ }^{9}$ However, the selectivity was strongly dependent on the ancillary ligand and the iridium chloride complex demonstrated diverging reactivity from the complex containing an aqua ligand. We also noted that the iridiumbound water molecule can be easily replaced by acetonitrile, while the chloride derivative does not undergo exchange with acetonitrile but exchanges partly with water when solubilized in aqueous solvents. ${ }^{10}$

Based on these observations, we were hypothesizing that the ancillary ligand in these complexes plays a distinct role in controlling the reactivity of the iridium center. We therefore targeted a set of triazolylidene pyridyl iridium complexes containing different neutral or anionic ancillary ligands to evaluate their impact on the catalytic activity. Here we demonstrate that these ancillary ligands strongly influence whether the iridium center catalyzes dehydrogenation or dehydration of benzyl alcohol. Ligand exchange experiments provide a direct correlation with catalytic activity and selectivity. These results underline the relevance of ancillary ligands and provide a rational approach to tailor the catalytic activity of the metal center to either dehydrogenation (aldehyde formation) or dehydration and etherification. 


\section{Results and Discussion}

Synthesis of complexes with different ancillary ligands. The synthesis of complexes $\mathbf{1}$ and $\mathbf{2}$ was previously reported. ${ }^{4 \mathrm{c}}$ The dicationic complex $\mathbf{2}$ was prepared by chloride abstraction from $\mathbf{1}$ with silver triflate in the presence of water. The same methodology was employed for the synthesis of the new complexes 3 and $\mathbf{4}$. Compound 3 was obtained in good yields ( $80 \%)$ from 1 and $\mathrm{AgOTf}$ in $\mathrm{CH}_{2} \mathrm{Cl}_{2}$ that was saturated with gaseous $\mathrm{NH}_{3}$, ${ }^{11}$ or alternatively by using an excess of ammonium hydroxide solution. No side products were observed in the later procedure such as a potential hydroxo complex, or the aqua complex 2 . This high selectivity for ammonia coordination suggests a stronger $\mathrm{Ir}-\mathrm{NH}_{3}$ bond in comparison to $\mathrm{Ir}-\mathrm{OH}_{2}$. Similarly, AgOTfmediated chloride abstraction in the presence of aniline afforded complex 4 , which was obtained as a yellow powder in moderate yields of $65 \%$. When performing the reaction with AgOTf in $\mathrm{MeCN}$, complex 5 was obtained. ${ }^{4 \mathrm{c}}$
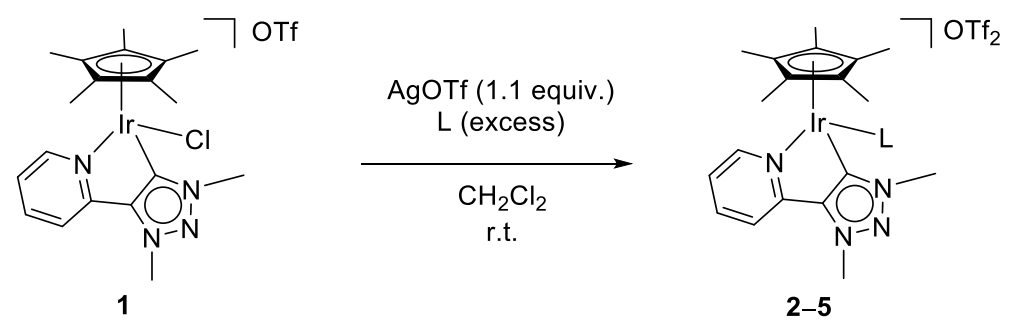
$\mathrm{L}=\left(\mathrm{OH}_{2}\right) 2$
$\left(\mathrm{NH}_{3}\right) 3$
$\left(\mathrm{NH}_{2} \mathrm{Ph}\right) 4$
(NCMe) 5

Scheme 1. Iridium complexes with variable ancillary ligands.

Complexes 3 and $\mathbf{4}$ were characterized by NMR spectroscopy. The pyridyl moiety of both 3 and 4 shows only slight changes when compared to the chloride derivative $\mathbf{1}$. Most diagnostic is the shift of the ortho pyridyl signal to lower field with respect to $1\left(\delta_{\mathrm{H}}=9.01 \mathrm{in} \mathbf{1} v s \delta_{\mathrm{H}}=9.16\right.$ and $9.31 \mathrm{ppm}$ for complexes 3 and $\mathbf{4}$, respectively (acetone- $d_{6}$ solution). A similar downfield shift was previously noted for complex $2\left(\delta_{\mathrm{H}}=9.32 \mathrm{ppm}\right)$, indicative of stronger pyridyl coordination to the metal center and therefore a direct consequence of the change of the ancillary ligand from an anionic chloride to a neutral amine. The spectrum of complex $\mathbf{3}$ further shows a signal at $\delta_{\mathrm{H}}=4.10$ for the coordinated $\mathrm{NH}_{3}$ ligand. The broad nature of this resonance suggests either hindered rotation about the $\mathrm{Ir}-\mathrm{N}$ bond, or ligand exchange rates that are close to the ${ }^{1} \mathrm{H}$ NMR frequency. The resonance is much less shielded in this iridium(III) complex than when ammonia is bound to other iridium centers. ${ }^{12}$ In complex 4 , the $\mathrm{NH}_{2}$ protons of the aniline ligand appear as two distinct $\mathrm{AB}$ doublets at 7.39 and $7.27 \mathrm{ppm}\left({ }^{2} J_{\mathrm{HH}}=10 \mathrm{~Hz}\right)$, a direct consequence of the chirality at iridium. In the ${ }^{13} \mathrm{C}\left\{{ }^{1} \mathrm{H}\right\}$ NMR spectra, the iridium-bound $\mathrm{C}_{\mathrm{trz}}$ nucleus appears at $\delta_{\mathrm{C}}$ $=153.5$ for complex $\mathbf{3}$ and $155.9 \mathrm{ppm}$ for $\mathbf{4}$, well within the range of triazolylidene resonances of similar compounds. ${ }^{13}$ 
Single crystals suitable for X-ray diffraction analysis of complexes $\mathbf{3}$ and $\mathbf{4}$ were obtained from slow evaporation of either a $\mathrm{CH}_{2} \mathrm{Cl}_{2}$ solution of $\mathbf{3}$ or by diffusion of $\mathrm{Et}_{2} \mathrm{O}$ into a $\mathrm{CH}_{2} \mathrm{Cl}_{2}$ solution of complex 4 . The molecular structures confirm the expected ligand connectivity with the typical piano-stool geometry of iridium featuring a $\mathrm{N}, \mathrm{C}$-bidentate chelating pyridyl-carbene ligand and the amine ligand as the three legs (Fig. 1). Complex 3 crystallized with an additional molecule of water, which is supported by hydrogen bonding with both the $\mathrm{NH}_{3}$ ligand and the triflate counterion (Fig. 1a). The coordination of $\mathrm{NH}_{3}$ and not $\mathrm{H}_{2} \mathrm{O}$ is another indication that the $\mathrm{Ir}-\mathrm{NH}_{3}$ bond is stronger than the $\mathrm{Ir}-\mathrm{OH}_{2}$ bond. The $\mathrm{Ir}-\mathrm{C} 1$ bond distance is 2.029(3) $\AA$, identical within esds to that found for related complexes such as the aqua derivative $\mathbf{2}$ ( $\mathrm{Ir}-\mathrm{C} 1$ in $\mathbf{2}$ is $2.030(2) \AA){ }^{4 \mathrm{c}}$ These identical values indicate that the Ir-triazolylidene bond is not significantly affected by the substitution of the ancillary ligand. Interestingly, the Ir-triazolylidene bond in the chloride complex $\mathbf{1}$ is marginally shorter (2.017(2) $\AA$ ) than that in the dicationic complexes $\mathbf{2}$ and 3. Such a decreased bond length does not reflect the reduced charge of the metal center (monocationic in $\mathbf{1}$ vs dicationic in $\mathbf{2}$ and $\mathbf{3}$ ). The $\mathrm{Ir}-\mathrm{N}(5)$ bond distance to the $\mathrm{NH}_{3}$ ligand is 2.127(2) $\AA$, slightly shorter than the iridium- pyridyl bond length ( $\mathrm{Ir}-\mathrm{N}(4)=2.140(2) \AA)$, and also shorter than in a related phosphine complex. ${ }^{11}$

In the single crystals of complex $\mathbf{4}$, the carbene ligand is completely disordered over the two coordination sites of iridium occupied by the chelate. These two configurations represent the enantiomers of complex 4 due to invertion of chirality at iridium (Fig. 1b, 1c). While both enantiomers of 3 co-crystallized in a defined translational order (as indicated by the centrosymmetric point group $\mathrm{P} 2{ }_{1} / \mathrm{c}$ ), the enantiomers of complex 4 are completely disordered. This disorder demonstrates the steric similarity of the pyridyl fragment and the dimethylsubstituted triazolylidene heterocycle. Hence, this specific triazolylidene is an excellent structural substitute of pyridine, as previously noted for ruthenium complexes. ${ }^{14}$ Since the disorder is wellresolved, refinement converges with high reliability and bond lengths and angles are well-defined. Accordingly, the Ir- $\mathrm{C}_{\mathrm{trz}}$ bond distance Ir-C1a 1.990(6) $\AA$ and Ir-C1b 1.994(7) $\AA$ are smaller and outside the $3 \sigma$ range when compared to the corresponding bond lengths in complexes 2 (2.029(3) $\AA$ ) and 3 (2.030(2) $\AA$; Table 1). ${ }^{15}$ This alteration may in part be due to a $\pi$ interaction between the pyridyl heterocycle and the phenyl group of the aniline ligand. In compensation for the relatively short Ir- $\mathrm{C}_{\text {trz }}$ bond, the Ir- $\mathrm{N}_{\text {pyr }}$ bond (Ir-N4a 2.156(5) $\AA$, Ir-N4b 2.174(6) $\AA$ ) is stretched in both enantiomers when compared with the structures of $\mathbf{1}$ and $\mathbf{3}$, and is similar to the bond length observed for the iridium-aniline bond, Ir-N5 2.179(2) $\AA$. 
a)

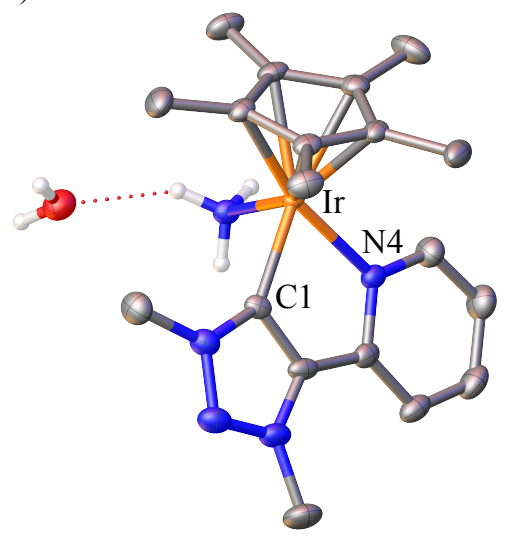

b)



c)

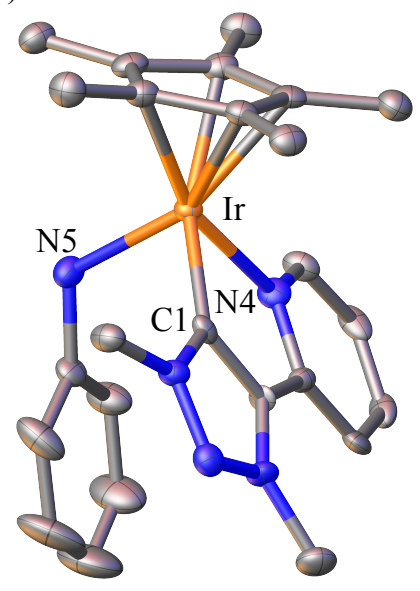

Figure 1. ORTEP representation (a) of the complex cations of $\mathbf{3}$ with the co-crystallized $\mathrm{H}_{2} \mathrm{O}$ molecule and $(b, c)$ of both configurations of complex 4 ; all ellipsoids at 50\% probability level, hydrogen atoms, and non-coordinating $\mathrm{OTf}^{-}$anions omitted for clarity.

Table 1. Selected bond lengths ( $\AA \dot{)}$ ) and angles $\left({ }^{\circ}\right)$ for complexes 3 and 4.

\begin{tabular}{llll}
\hline & $\mathbf{1}^{\mathrm{b}}$ & $\mathbf{3}$ & $\mathbf{4}$ \\
\hline $\mathrm{Ir}-\mathrm{C}_{\mathrm{trz}}$ & $2.017(2)$ & $2.029(3)$ & $1.990(6) / 1.994(7)$ \\
$\mathrm{Ir}-\mathrm{N}_{\mathrm{py}}$ & $2.129(2)$ & $2.140(2)$ & $2.156(5) / 2.174(6)$ \\
$\mathrm{Ir}-\mathrm{L}$ & 2.420 & $2.127(2)$ & $2.179(2)$ \\
$\mathrm{Ir}-\mathrm{Cg}{ }^{\text {a }}$ & 1.816 & 1.810 & 1.804 \\
$\mathrm{C}_{\text {trz }}-\mathrm{Ir}-\mathrm{C}_{\mathrm{py}}$ & 76.08 & $76.24(9)$ & $77.2(2) / 75.6(3)$ \\
\hline
\end{tabular}

${ }^{\mathrm{a}} \mathrm{Cg}$ refers to the centroid position of $\mathrm{Cp}^{*}$. ${ }^{\mathrm{b}}$ Data taken from ref. $4 \mathrm{c}$.

Ligand exchange experiments. While in aqueous solution, complex 1 exists in an ionic strength-dependent equilibrium with the corresponding solvento complex $2,{ }^{10}$ no such solvolysis was observed in $\mathrm{MeCN}$ and complex 1 remained unchanged. However, dissolving complex 2 in $\mathrm{MeCN}$ led to rapid ligand exchange and formation of complex $\mathbf{5}$, which is stable and does not transform back to the aqua complex even when dissolved in water. This behaviour highlights the preferred binding of $\mathrm{MeCN}$ over $\mathrm{H}_{2} \mathrm{O}$ in these triazolylidene iridium(III) complexes.

Therefore, the Ir- $\mathrm{L}$ bond strength was qualitatively evaluated for $\mathrm{NH}_{3}$ and aniline. To this end, the ammonia complex 3 was dissolved in acetone- $d_{6}$ and exposed to an excess (20 mol equiv.) of competitive ligands $\mathrm{H}_{2} \mathrm{O}, \mathrm{MeCN}$, and aniline, respectively (Scheme 2). Similarly, the aniline complex 4 was exposed to $\mathrm{H}_{2} \mathrm{O}, \mathrm{NCMe}$, and $\mathrm{NH}_{3}$ (as $\mathrm{NH}_{4} \mathrm{OH}$ solution in $\mathrm{H}_{2} \mathrm{O}$ ). NMR monitoring of these mixtures indicated that complex 3 remained intact and no traces of the other complexes were observed, irrespective of the added ligand. Likewise, complex 4 remained unaltered in the presence of $\mathrm{H}_{2} \mathrm{O}$ or $\mathrm{NCMe}$, however, addition of $\mathrm{NH}_{4} \mathrm{OH}$ induced immediate displacement of the coordinated aniline for $\mathrm{NH}_{3}$, indicated by the diagnostic signal at $\delta_{\mathrm{H}}=4.10$ 
for the coordinated $\mathrm{NH}_{3}$ protons. Ammonia coordination was also visually noticed by the instantaneous color change of the solution from dark to pale yellow upon addition of the ammonia solution. According to these experiments, the $\mathrm{Ir}-\mathrm{L}$ bond strength decreases in the sequence of $\mathrm{L}$ $=\mathrm{NH}_{3}>$ aniline $>\mathrm{MeCN}>\mathrm{H}_{2} \mathrm{O}$.

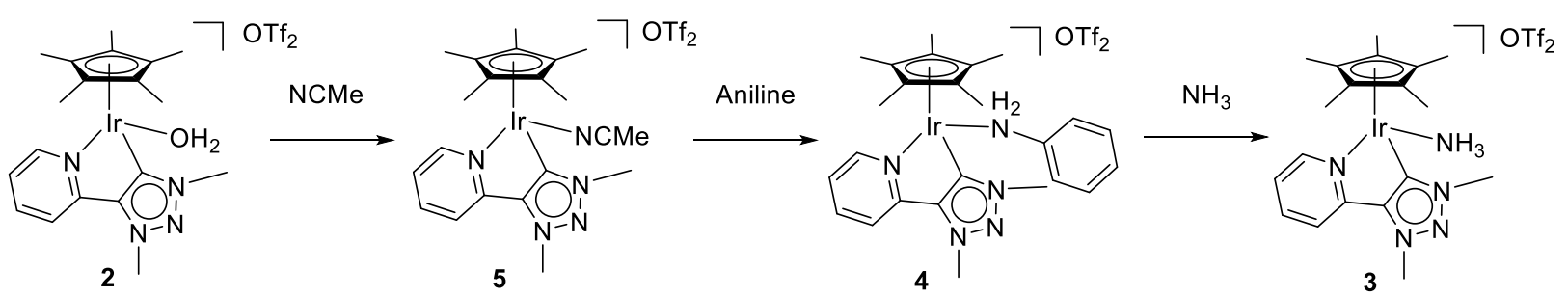

Scheme 2. Evaluation of the coordination ability of neutral ancillary ligands to iridium.

Catalytic acceptorless oxidation and ether formation. Iridium complexes $\mathbf{1}$ and $\mathbf{2}$ have shown excellent catalytic activity in oxidation reactions, which is imparted by the unique features of mesoionic triazolylidene ligands, ${ }^{13,16}$ especially in combination with a chelating pyridyl substituent. ${ }^{4 c, 17}$ For example, we recently reported the base-free etherification of benzyl alcohol induced by an iridium complex containing a triazolylidene ligand with a cyclometalated pyridyl fragment. ${ }^{8 b}$ Such etherification occurs through a dehydration pathway, while competitive dehydrogenation results in the formation of benzaldehyde (Scheme 3). ${ }^{8 a}$ Mechanistic investigations suggest that substrate coordination is turnover limiting. This step is obviously dependent on the type of ancillary ligand, and modulation of this ligand therefore offers an opportunity to tailor the catalytic activity. Based on these precedents, we tested the activity of different iridium complexes in this reaction. Etherification of benzyl alcohol was used as standard reaction, as the formation of the ether is slow and easily monitored.

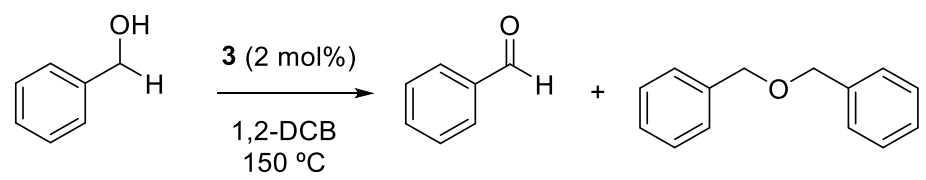

Scheme 3. Benzyl alcohol oxidation catalyzed by iridium NHC complexes.

When benzyl alcohol was heated to $150{ }^{\circ} \mathrm{C}$ in the presence of 2 mol\% of complex 3 in 1,2-dichlorobenzene, formation of benzaldehyde and dibenzyl ether was observed (Figure 2; Table S1). At early stages of the reaction, benzaldehyde is produced selectively, though after 30 min, minor quantities (6\%) of the symmetric dibenzyl ether were detected. After $4 \mathrm{~h}, 82 \%$ 
conversion was noted, though the selectivity eroded considerably and the benzaldehyde $v s$ dibenzyl ether ratio was just about 2:1 (57\% vs 25\% spectroscopic yield). This ratio remained essentially constant up to high conversions. Substrate turnover rates gradually slowed down and $97 \%$ conversion required up to $24 \mathrm{~h}$.



Figure 2. Oxidation of benzyl alcohol catalyzed by iridium complex 3 () produces initially only benzaldehyde (dehydrogenation), while prolonged reaction times lead to increasing formation of dibenzyl ether (dehydration); this change in selectivity presumably arises from a gradual modification of the catalytically active species over time ( $2 \mathrm{~mol} \%$ catalyst loading, $150{ }^{\circ} \mathrm{C}$, in 1,2-DCB; conversions determined by ${ }^{1} \mathrm{H}$ NMR spectroscopic analysis in $\mathrm{CDCl}_{3}$ using hexamethylbenzene as internal standard; note that the \% given for the symmetric ether refers to the $\%$ of alcohol converted to ether).

Both the catalytic activity as well as the etherification $v s$ dehydrogenation selectivity were strongly affected by the catalyst loading. When four parallel reactions were performed in the presence of $1 \%, 2 \%, 3 \%$, and $5 \%$ catalyst 3 , respectively, dehydrogenation was favored for higher catalyst loadings. For example, runs with $5 \mathrm{~mol} \%$ catalyst displayed a 9:1 selectivity towards benzaldehyde formation after $2 \mathrm{~h}$, while an identical run with less catalyst loading showed a gradual decrease to $6: 1$ (3 mol\%), to $3: 1(2 \mathrm{~mol} \%)$ to eventually provide only a $2: 1$ selectivity at $1 \mathrm{~mol} \%$ loading (Figure 3). This trend is even more pronounced after longer reaction times when almost full conversion was reached even with 1 mol\% of complex 3 (lower than 1:1 ratio with $51 \%$ ether $v s 42 \%$ aldehyde). 


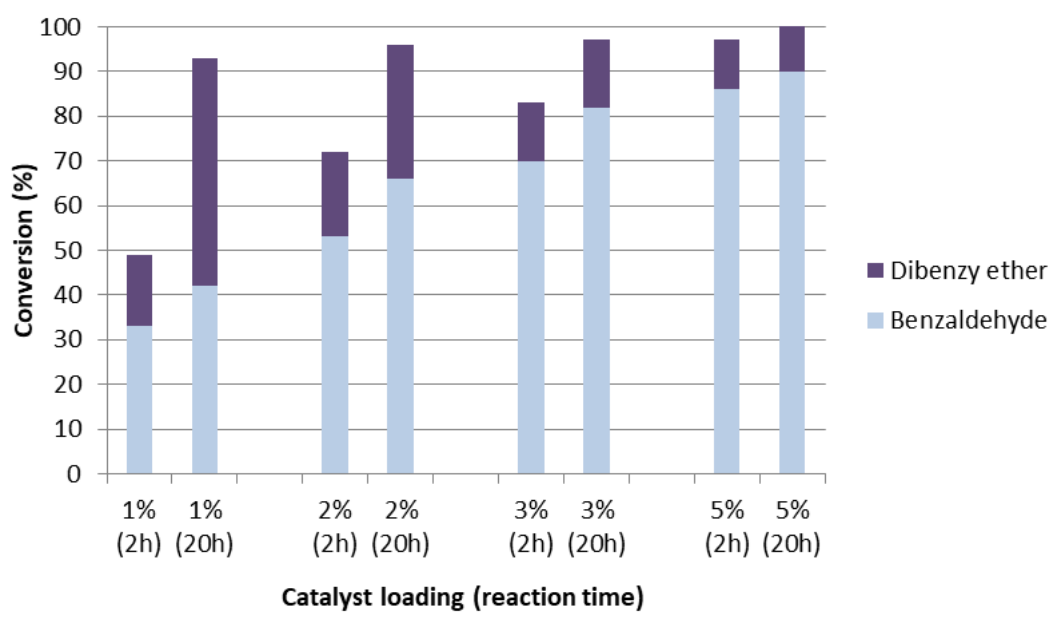

Figure 3. BnOH oxidation catalyzed by iridium complex 3 at different catalyst loadings ( $2 \mathrm{~h}$ (left) and $20 \mathrm{~h}$ (right), $150{ }^{\circ} \mathrm{C}, 1,2-\mathrm{DCB}$ ). Conversions determined by ${ }^{1} \mathrm{H}$ NMR spectroscopic analysis in $\mathrm{CDCl}_{3}$ using hexamethylbenzene as internal standard. Note that the \% given for the symmetric ether refers to the $\%$ of alcohol converted in ether.

A few more conclusions can be extracted from these measurements. Firstly, the selectivity towards benzaldehyde is very high at the beginning of the reaction, yet ether formation is preferred at later stages ( $c f 2$ and $20 \mathrm{~h}$ selectivity with $1 \mathrm{~mol} \%$ loading). Therefore, ether formation is dependent on the reaction time, and not on a specific stage of conversion. Secondly, dehydration and dehydrogenation are two distinct catalytic cycles, with irreversible product formation. This is best demonstrated by the consistent product ratio at $5 \mathrm{~mol} \%$ catalyst loading after $2 \mathrm{~h}$ and $20 \mathrm{~h}$. Hence, the aldehyde is not an intermediate for the formation of the ether product. Based on these considerations, we surmise that a catalytically active species is formed initially that is closely related to complex $\mathbf{3}$, for example a fragile iridium hydride, ${ }^{18}$ which catalyzes the dehydrogenation and formation of the aldehyde. A gradual transformation of this species is then supposed to provide a different catalyst with a so far elusive structure that promotes the formation of ether rather than dehydrogenation.

Further support for such a process was obtained from experiments aimed at testing the stability of the catalytically active species derived from complex $\mathbf{3}$ upon repetitive additions of substrate. Sequential addition of 20 equivalents of benzyl alcohol every $24 \mathrm{~h}$ revealed essentially quantitative conversions for the first four batches, and a reduced $65 \%$ conversion for the fifth batch, pointing towards some catalyst deactivation after a few days (Table 2). The continued activity of the catalyst for about $100 \mathrm{~h}$ at $150{ }^{\circ} \mathrm{C}$ indicates a high robustness of the active species. In agreement with experiments with variable catalyst loading, the selectivity of the catalyst changes upon prolonged activity. While the product mixture demonstrated a 4:1 selectivity towards the benzaldehyde $v s$ dibenzyl ether for the conversion of the first batch of benzaldehyde (entry 1), the mixture is equal after the second run (entry 2 ), and then gradually changes to 
predominant ether formation (entries 3-5). When analysing the selectivity for each added batch of substrate (Table S2), we note an inversed preference towards the dibenzyl ether for all subsequent batches (1:4 aldehyde/ether ratio for second, third, and fourth batch). ${ }^{19}$ This preference for dibenzyl ether formation is in agreement with the gradual transformation of the iridium species from a dehydrogenation catalyst to a dehydration catalyst, corroborating the conclusions drawn from modulation of catalyst loadings ( $c f$ Figure 3 ). This second catalyst is exceptionally stable and remains active at $150^{\circ} \mathrm{C}$ for several days.

Table 2. Catalyst reuse and stability during consecutive additions of benzyl alcohol. ${ }^{\mathrm{a}}$

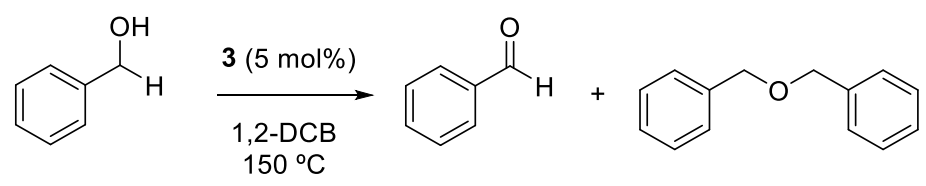

\begin{tabular}{ccccccc}
\hline Entry & $\begin{array}{c}\text { Conversion } \\
(\%)^{b}\end{array}$ \\
\hline 1 & $0.4 \mathrm{mmol}$ & 100 & 82 & 18 & 20 & 4.5 \\
2 & $+0.4 \mathrm{mmol}$ & 100 & 50 & 50 & 40 & 1.0 \\
3 & $+0.4 \mathrm{mmol}$ & 100 & 39 & 61 & 60 & 0.6 \\
4 & $+0.4 \mathrm{mmol}$ & 99 & 34 & 65 & 79 & 0.7 \\
5 & $+0.4 \mathrm{mmol}$ & 91 & 37 & 54 & 92 & 0.7 \\
\hline
\end{tabular}

a Conditions: benzyl alcohol $(41 \mu \mathrm{L}, 0.4 \mathrm{mmol})$, complex 3 (16 mg, $0.02 \mathrm{mmol}, 5 \mathrm{~mol} \%), 1,2-$ dichlorobenzene $(2 \mathrm{~mL}), 150^{\circ} \mathrm{C}$, sealed tube; $24 \mathrm{~h}$ interval before addition of the next portion of substrate. ${ }^{\mathrm{b}}$ It refers to total conversion. Determined by ${ }^{1} \mathrm{H}$ NMR spectroscopic analysis. Note that the $\%$ given for the symmetric ether refers to the $\%$ of alcohol converted in ether.

The role of the ancillary ligand. We previously reported that in these triazolylidene iridium complexes the ancillary ligand plays a pivotal role in imparting catalytic activity. ${ }^{9}$ While the chloride complex 1 was inactive in silane-induced etherification of alcohols, the corresponding cationic aqua complex $\mathbf{2}$ shows excellent activity. We were therefore interested to evaluate the impact of various ancillary ligands on the catalytic activity and selectivity of the triazolylidene iridium complex and have monitored the catalytic conversion of benzyl alcohol in the presence of complexes $\mathbf{2}, \mathbf{3}$ and 4 , as well as their deprotonated analogues $\mathbf{6 , 7}$ and 8 (Figure 4). 


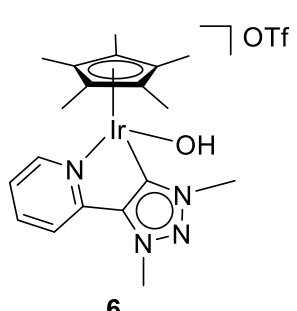

6

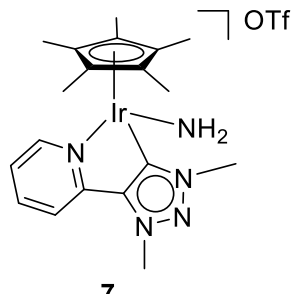



Figure 4. Monocationic complexes 6-8 obtained from deprotonation of complexes 2, 3 and $\mathbf{4}$, respectively.

The results of this catalyst screening are compiled in Table 3. Inspection of these results evidences that the different ancillary ligands affect the outcome of the catalysis significantly, both in terms of activity and selectivity. Comparison of complexes 2-4 (entries 4-12) shows that the aqua complex 2 is more active ( $78 \%$ conversion after $0.5 \mathrm{~h})$ than the aniline complex $4(62 \%$ conversion), while the ammonia complex 3 is the slowest of this series ( $46 \%$ conversion). A similar trend was observed when comparing the conversions after $6 \mathrm{~h}(97 \%, 91 \%$, and $86 \%$ for $\mathbf{2}$, $\mathbf{4}$, and $\mathbf{3}$, respectively). In contrast, the parent chloride complex $\mathbf{1}$ is considerably less active and reaches only $25 \%$ conversion after $0.5 \mathrm{~h}$, and $70 \%$ after $24 \mathrm{~h}$ (entries 1-3). Likewise, solvent changes were not productive. A reaction with complex 2 in acetone at $60{ }^{\circ} \mathrm{C}$ gave an appreciable $50 \%$ conversion after $24 \mathrm{~h}$, while reactions in $\mathrm{H}_{2} \mathrm{O}$ at $100{ }^{\circ} \mathrm{C}$ led to only $7 \%$ conversion within the same time span.

Most importantly, the three complexes with neutral ancillary ligands have not only distinct activities, but also diverging selectivity. While the aqua complex 2 predominantly forms the dibenzyl ether product (benzaldehyde/ether ratio is 0.4 ; entries 4,5), the ammonia complex 3 displays a marked preference for benzaldehyde formation (initial benzaldehyde/ether ratio is 6.7). As discussed above, this ratio erodes with increasing reaction time and converges to about 2 at higher conversions. The aniline complex 4 does not show any change of ratio throughout the reaction and forms the ether and the aldehyde in equal amounts (entries 10-12).

Hence while the catalytic activity decreases along the series $2\left(\mathrm{~L}=\mathrm{OH}_{2}\right)>\mathbf{4}\left(\mathrm{PhNH}_{2}\right)>$ $3\left(\mathrm{NH}_{3}\right)$, the selectivity towards dehydrogenation and benzaldehyde formation increases in the same order. This sequence is consistent with the above observation that for complex $\mathbf{3}$, slower conversions (as induced for example by lower catalyst loadings) enhances the preference towards benzaldehyde formation. Moreover, the sequence correlates with the bond strength deduced from ligand substitution experiments (see above). Independent of the underlying mechanism, these results highlight the pivotal role of the ancillary ligand to control activity and selectivity of the iridium center. 
Table 3. $\mathrm{BnOH}$ oxidation catalyzed by iridium complexes 2-4 and 6-8; influence of the ancillary ligands. ${ }^{\mathrm{a}}$<smiles>O=C([CH+]c1ccccc1)c1ccc(COCc2ccccc2)cc1</smiles>



Entry [Ir] $\mathrm{X}$ or L Time Conv.

\begin{tabular}{|c|c|c|c|c|c|c|c|}
\hline 1 & 1 & $\mathrm{Cl}$ & $0.5 \mathrm{~h}$ & 25 & 25 & $<1$ & -- \\
\hline 2 & & & $6 \mathrm{~h}$ & 80 & 63 & 17 & 3.7 \\
\hline 3 & & & $24 \mathrm{~h}$ & 92 & 70 & 22 & 3.2 \\
\hline 4 & 2 & $\mathrm{OH}_{2}$ & $0.5 \mathrm{~h}$ & 78 & 22 & 56 & 0.4 \\
\hline 5 & & & $6 \mathrm{~h}$ & 97 & 24 & 73 & 0.3 \\
\hline 6 & & & $24 \mathrm{~h}$ & n.d. & n.d. & n.d. & n.d. \\
\hline 7 & 3 & $\mathrm{NH}_{3}$ & $0.5 \mathrm{~h}$ & 46 & 40 & 6 & 6.7 \\
\hline 8 & & & $6 \mathrm{~h}$ & 86 & 59 & 27 & 2.2 \\
\hline 9 & & & $24 \mathrm{~h}$ & 97 & 62 & 35 & 1.8 \\
\hline 10 & 4 & $\mathrm{NH}_{2} \mathrm{Ph}$ & $0.5 \mathrm{~h}$ & 62 & 33 & 29 & 1.1 \\
\hline 11 & & & $6 \mathrm{~h}$ & 91 & 45 & 46 & 1.0 \\
\hline 12 & & & $24 \mathrm{~h}$ & 98 & 47 & 51 & 0.9 \\
\hline 13 & $6^{5}$ & $\mathrm{OH}$ & $0.5 \mathrm{~h}$ & 16 & 16 & $<1$ & - \\
\hline 14 & & & $6 \mathrm{~h}$ & 22 & 22 & $<1$ & - \\
\hline 15 & & & $24 \mathrm{~h}$ & 24 & 24 & $<1$ & \\
\hline 16 & $6^{c}$ & $\mathrm{OH}$ & $0.5 \mathrm{~h}$ & 50 & 45 & 5 & 9.0 \\
\hline 17 & & & $6 \mathrm{~h}$ & 71 & 59 & 12 & 4.9 \\
\hline 18 & & & $24 \mathrm{~h}$ & 86 & 67 & 19 & 3.5 \\
\hline 19 & $7^{c}$ & $\mathrm{NH}_{2}$ & $0.5 \mathrm{~h}$ & 38 & 38 & $<1$ & -- \\
\hline 20 & & & $6 \mathrm{~h}$ & 71 & 58 & 13 & 4.5 \\
\hline 21 & & & $24 \mathrm{~h}$ & 85 & 67 & 18 & 3.7 \\
\hline 22 & $8^{c}$ & $\mathrm{NHPh}$ & $0.5 \mathrm{~h}$ & 54 & 46 & 8 & 5.7 \\
\hline 23 & & & $6 \mathrm{~h}$ & 82 & 70 & 12 & 5.8 \\
\hline 24 & & & $24 \mathrm{~h}$ & 88 & 77 & 11 & 7.0 \\
\hline
\end{tabular}

The activities of complexes $\mathbf{2}-\mathbf{4}$ were compared to those of the analogous complexes $\mathbf{6}-$ 8 containing the corresponding deprotonated ligands. Complex 6 with an ancillary hydroxyl 
ligand, was synthesized from the corresponding aqua derivative 2 in $\mathrm{CH}_{2} \mathrm{Cl}_{2}$ using 1 molequiv. of lithium bis(trimethylsilyl)amide (LiHMDS), exploiting the relatively high aciditiy of the iridium-coordinated water ligand $(\mathrm{pKa}=8.3) .{ }^{10}$ The hydroxyl complex 6 was isolated as an orange solid in moderate yields (51\%). Compound 6 is highly hygroscopic, and probably for this reason attempts to obtain microanalysis were unsuccessful. A catalytic test using complex $\mathbf{6}$ gave results that were identical to those of runs in which complex $\mathbf{6}$ was generated in situ from complex 2 and 1 molequiv. LiHMDS (entries 13-15), and therefore, further catalytic experiments were performed by deprotonating the neutral ligand in situ. Of note, however, deprotonation with LHMDS afforded a catalytic species that was less active than when $\mathrm{KO} t \mathrm{Bu}$ was used as a base (entries 16-18). The activity difference is significant, e.g. $50 \mathrm{vs} 18 \%$ conversion after $0.5 \mathrm{~h}$, and almost quantitative formation after $24 \mathrm{~h}$ when $\mathrm{KO} t \mathrm{Bu}$ was used, while the catalyst generated with LHMDS reached a modest $24 \%$ conversion. Independent of the deprotonation method, complex 6 is considerably less active than the analogous protonated aqua complex 2 (entries 4-6). Remarkably, the selectivity was inverted, and while the neutral aqua complex produced predominantly the ether product, the hydroxyl complex $\mathbf{6}$ greatly favored formation of benzaldehyde, especially at early reaction stages (benzyldehyde/ether ratio is 9 after $0.5 \mathrm{~h}$ and at $50 \%$ conversion, entry 16$)$.

The same deprotonation methodology was employed for generating complexes $\mathbf{7}$ and $\mathbf{8}$ in situ from 1 molequiv. $\mathrm{KO} t \mathrm{Bu}$ and complex $\mathbf{3}$ and $\mathbf{4}$, respectively. With these complexes, the activity is lower when compared to the performance of their parent complexes $\mathbf{3}$ and $\mathbf{4}$ with neutral ancillary ligands, though the difference is less pronounced than for the $\mathrm{OH}_{2} / \mathrm{OH}^{-}$pair 2 and 6. With all complexes 6-8, final conversions did not exceed $90 \%$, while all the parent complexes $\mathbf{2}-$ 4 with neutral ligands converted benzyl alcohol in $>97 \%$. Like the hydroxyl complex 6 , complexes $\mathbf{7}$ and $\mathbf{8}$ produced predominantly benzaldehyde, with only small quantities of dibenzyl ether formed throughout the entire reaction time (benzaldehyde/ether ratio is about 5). This selectivity is more pronounced than that of the ammonia complex $\mathbf{3}$, and contrasts with the 1:1 unselective reaction of the aniline complex 4 . These observations suggest that the presence of a neutral ancillary ligand facilitates the etherification process while anionic ligands are more selective towards the dehydrogenation pathway and the formation of benzaldehyde. The easy decoordination of neutral ancillary ligands may be key for the higher catalytic activity of complexes 2-4, while anionic ligands may provide easier access to a transient hydride as the critical species for substrate dehydrogenation.

Decoordination was probed by exposing complex 2 to 20 molequiv. benzyl alcohol in an NMR experiment ( $0.05 \mathrm{M}$ acetone solution). The spectrum clearly revealed the disappearance of the signal for coordinated water at $\delta_{\mathrm{H}}=2.79-3.37$, suggesting a ligand substitution from $\mathrm{H}_{2} \mathrm{O}$ to ROH. In contrast, the aniline complex 4 does not undergo any spectroscopic change when 
exposed to benzyl alcohol, arguably due to a stronger $\operatorname{Ir}-\mathrm{N}_{\text {aniline }}$ bond, which is in agreement with the lower catalytic activity of this complex compared to the aqua complex 2.

\section{Conclusions}

The iridium complexes $\mathbf{3}$ and $\mathbf{4}$ with ammonia and aniline ancillary ligands are easily accessible via chloride abstraction from the parent chloride complex 1. Competition experiments revealed that the $\mathrm{NH}_{3}$ ligand is more strongly bound to iridium than acetonitrile, aniline or water and does not undergo exchange with the former. Complex $\mathbf{3}$ was demonstrated to be an effective and robust catalyst for both etherification and dehydrogenation of benzyl alcohol. The selectivity of the catalysis is highly dependent on catalyst concentration, favoring dehydrogenation over etherification at lower catalyst loadings and vice versa. The catalytic process is highly dependent on the ancillary ligands in terms of rates, and selectivity. In general, the lability of the neutral ligands $\left(\mathrm{H}_{2} \mathrm{O}>\right.$ aniline $\left.>\mathrm{NH}_{3}\right)$ enhances catalytic activity and as a consequence, complexes with neutral ancillary ligands are more efficient catalyst than those with a deprotonated monoanionic ancillary ligand. While the complexes with anionic ancillary ligands are less active catalysts, they show better selectivity towards dehydrogenation (aldehyde formation) as opposed to dehydration (ether formation). The choice of ancillary ligand and catalyst concentration therefore allows to rationally switch the selectivity of the reaction to either obtain the ether product or the aldehyde. Such catalyst multi-tasking offers attractive opportunities for cascade transformations mediated by one single catalyst.

\section{Experimental}

General. The metalation reaction was carried out under a nitrogen atmosphere using standard Schlenk techniques and all the reagents and solvents were used as obtained from commercial sources. Complexes 1 and 2 were synthesized as previously reported without modifications. ${ }^{4 a}$ Microwave reactions were performed in a Biotage Initiator 2.0 reactor with high absorption. Unless specified, NMR spectra were recorded at $25{ }^{\circ} \mathrm{C}$ on Bruker spectrometers operating at 300 or $400 \mathrm{MHz}\left({ }^{1} \mathrm{H} \mathrm{NMR}\right)$ and 75 or $100 \mathrm{MHz}\left({ }^{13} \mathrm{C}\left\{{ }^{1} \mathrm{H}\right\}\right.$ NMR) respectively. Chemical shifts $(\delta)$ are expressed in ppm downfield from tetramethylsilane using the residual protonated solvent as an internal standard. Assignments are based on homo- and hetero-nuclear shift correlation spectroscopy. All the cationic complexes show a quartet around $120 \mathrm{ppm}$ in the ${ }^{13} \mathrm{C} \mathrm{NMR}$ spectrum due to the OTf counterion. Elemental analysis was performed on an Exeter Analytical CE440 elemental analyzer, by the Microanalytical Laboratory at the University College Dublin, Ireland.

Compound 3. Complex 1 (93 mg, $0.14 \mathrm{mmol})$ was dissolved in $\mathrm{CH}_{2} \mathrm{Cl}_{2}(10 \mathrm{~mL})$ and $\mathrm{AgOTf}(38$ $\mathrm{mg}, 0.15 \mathrm{mmol})$ and an ammonium hydroxide solution $(15 \mathrm{M}, 50 \mu \mathrm{L}, 0.75 \mathrm{mmol})$ and stirred for 2 hours. The mixture was filtered through Celite and the volume of the filtrate reduced to $1 \mathrm{~mL}$. 
Upon addition of $\mathrm{Et}_{2} \mathrm{O}$ a precipitate formed, which was collected by filtration and dried in vacuo, thus affording 3 as a pale yellow solid (88 mg, 79\%). ${ }^{1} \mathrm{H}$ NMR $\left(\mathrm{CD}_{2} \mathrm{Cl}_{2}, 400 \mathrm{MHz}\right): \delta=8.88$ $\left(\mathrm{ddd},{ }^{5} J_{\mathrm{HH}}=0.8,{ }^{4} J_{\mathrm{HH}}=1.4,{ }^{3} J_{\mathrm{HH}}=5.7 \mathrm{~Hz}, 1 \mathrm{H}, \mathrm{H}_{\mathrm{py}}\right), 7.90\left(\mathrm{td},{ }^{4} J_{\mathrm{HH}}=1.4,{ }^{3} J_{\mathrm{HH}}=7.8 \mathrm{~Hz}, 1 \mathrm{H}, \mathrm{H}_{\mathrm{py}}\right)$, $7.88\left(\mathrm{ddd},{ }^{5} J_{\mathrm{HH}}=0.8,{ }^{4} J_{\mathrm{HH}}=1.4,{ }^{3} J_{\mathrm{HH}}=7.8 \mathrm{~Hz}, 1 \mathrm{H}, \mathrm{H}_{\mathrm{py}}\right), 7.45\left(\mathrm{ddd},{ }^{4} J_{\mathrm{HH}}=1.4,{ }^{3} J_{\mathrm{HH}}=5.7,7.8\right.$ $\left.\mathrm{Hz}, 1 \mathrm{H}, \mathrm{H}_{\mathrm{py}}\right), 4.44,4.30\left(2 \mathrm{x} \mathrm{s}, 3 \mathrm{H}, \mathrm{NCH}_{3}\right), 3.61$ (br s, $\left.3 \mathrm{H}, \mathrm{NH}_{3}\right), 1.74\left(\mathrm{~s}, 15 \mathrm{H}, \mathrm{CpCH}_{3}\right) .{ }^{13} \mathrm{C}\left\{{ }^{1} \mathrm{H}\right\}$ $\operatorname{NMR}\left(\mathrm{CD}_{2} \mathrm{Cl}_{2}, 100 \mathrm{MHz}\right): \delta=153.8\left(\mathrm{C}_{\mathrm{py}}\right), 153.6\left(\mathrm{C}_{\mathrm{trz}}-\mathrm{Ir}\right), 149.4\left(C_{\mathrm{py}}-\mathrm{C}_{\mathrm{trz}}\right), 149.1\left(C_{\mathrm{trz}}-\mathrm{C}_{\mathrm{py}}\right)$, 140.1, 126.0, $121.6\left(3 \times \mathrm{C}_{\mathrm{py}}-\mathrm{H}\right), 90.8\left(\mathrm{C}_{\mathrm{Cp}}\right), 40.0,38.8\left(2 \times \mathrm{N}-\mathrm{CH}_{3}\right), 8.6\left(\mathrm{Cp}-\mathrm{CH}_{3}\right)$. Anal. Calcd. for $\mathrm{C}_{21} \mathrm{H}_{28} \mathrm{~F}_{6} \mathrm{IrN}_{5} \mathrm{O}_{6} \mathrm{~S}_{2}$ : C: $30.88 ; \mathrm{H}: 3.46$; N: 8.57. Found: C: $30.48 ; \mathrm{H}: 3.24 ; \mathrm{N}: 8.21 \%$.

Compound 4. Complex 1 (80 mg, $0.12 \mathrm{mmol})$ was dissolved in $\mathrm{CH}_{2} \mathrm{Cl}_{2}(10 \mathrm{~mL})$ and $\mathrm{AgOTf}(33$ $\mathrm{mg}, 0.13 \mathrm{mmol}$ ) was added, followed by aniline $(12 \mu \mathrm{L}, 0.13 \mathrm{mmol})$. The mixture was stirred for $16 \mathrm{~h}$ and filtered through Celite and the filtrate was concentrated to $1 \mathrm{~mL}$. Upon addition of $\mathrm{Et}_{2} \mathrm{O}$ a precipitate formed, which was isolated by filtration and dried in vacuo to yield complex $\mathbf{4}$ as a dark yellow solid (65 mg, 62\%). ${ }^{1} \mathrm{H} \mathrm{NMR}\left(\mathrm{CD}_{2} \mathrm{Cl}_{2}, 400 \mathrm{MHz}\right): \delta=9.10\left(\mathrm{~d},{ }^{3} J_{\mathrm{HH}}=5.8 \mathrm{~Hz}, 1 \mathrm{H}\right.$, $\left.\mathrm{H}_{\mathrm{py}}\right), 7.96\left(\mathrm{td},{ }^{4} J_{\mathrm{HH}}=1.3,{ }^{3} J_{\mathrm{HH}}=7.8 \mathrm{~Hz}, 1 \mathrm{H}, \mathrm{H}_{\mathrm{py}}\right), 7.69\left(\mathrm{~d},{ }^{3} J_{\mathrm{HH}}=7.8 \mathrm{~Hz}, 1 \mathrm{H}, \mathrm{H}_{\mathrm{py}}\right), 7.50(\mathrm{ddd}$, $\left.{ }^{4} J_{\mathrm{HH}}=1.3,{ }^{3} J_{\mathrm{HH}}=5.8,7.8 \mathrm{~Hz}, 1 \mathrm{H}, \mathrm{H}_{\mathrm{py}}\right), 6.96\left(\mathrm{~d},{ }^{2} J_{\mathrm{HH}}=10.3 \mathrm{~Hz}, 1 \mathrm{H}, \mathrm{NH}_{2}\right), 6.80\left(\mathrm{t},{ }^{3} J_{\mathrm{HH}}=7.7 \mathrm{~Hz}\right.$, $\left.1 \mathrm{H}, \mathrm{H}_{\mathrm{Ph}}\right), 6.72\left(\mathrm{t},{ }^{3} J_{\mathrm{HH}}=7.7 \mathrm{~Hz}, 2 \mathrm{H}, \mathrm{H}_{\mathrm{Ph}}\right), 6.71\left(\mathrm{~d},{ }^{2} J_{\mathrm{HH}}=10.3 \mathrm{~Hz}, 1 \mathrm{H}, \mathrm{NH}_{2}\right), 6.19\left(\mathrm{~d},{ }^{3} J_{\mathrm{HH}}=7.7\right.$ $\left.\mathrm{Hz}, 2 \mathrm{H}, \mathrm{H}_{\mathrm{Ph}}\right), 4.40,4.19\left(2 \mathrm{x} \mathrm{s}, 3 \mathrm{H}, \mathrm{N}-\mathrm{CH}_{3}\right), 1.72\left(\mathrm{~s}, 15 \mathrm{H}, \mathrm{Cp}-\mathrm{CH}_{3}\right) .{ }^{13} \mathrm{C}\left\{{ }^{1} \mathrm{H}\right\} \mathrm{NMR}\left(\mathrm{CD}_{2} \mathrm{Cl}_{2}, 100\right.$ $\mathrm{MHz}): \delta=156.2\left(\mathrm{C}_{\mathrm{trz}}-\mathrm{Ir}\right), 154.0\left(\mathrm{C}_{\mathrm{py}}-\mathrm{H}\right), 149.2\left(C_{\mathrm{trz}}-\mathrm{C}_{\mathrm{py}}\right), 148.7\left(C_{\mathrm{py}}-\mathrm{C}_{\mathrm{trz}}\right), 140.7\left(\mathrm{C}_{\mathrm{py}}-\mathrm{H}\right), 140.2$ $\left(\mathrm{C}_{\mathrm{Ph}}-\mathrm{N}\right), 128.0\left(\mathrm{C}_{\mathrm{Ph}}-\mathrm{H}\right), 126.8\left(\mathrm{C}_{\mathrm{py}}-\mathrm{H}\right), 124.8\left(\mathrm{C}_{\mathrm{Ph}}-\mathrm{H}\right), 121.7\left(\mathrm{C}_{\mathrm{py}}-\mathrm{H}\right), 120.0\left(\mathrm{C}_{\mathrm{Ph}}-\mathrm{H}\right), 91.8\left(\mathrm{C}_{\mathrm{Cp}}\right)$, 40.4, $38.7\left(2 \times \mathrm{N}-\mathrm{CH}_{3}\right), 8.7\left(\mathrm{Cp}-\mathrm{CH}_{3}\right)$. Anal. Calc. for $\mathrm{C}_{27} \mathrm{H}_{32} \mathrm{~F}_{6} \mathrm{IrN}_{5} \mathrm{O}_{6} \mathrm{~S}_{2}: \mathrm{C}: 36.32 ; \mathrm{H}: 3.61 ; \mathrm{N}$ : 7.84. Found: C: 36.17 ; H: 3.44; N: $7.64 \%$.

Ligand exchange experiments. Compound 2 was dissolved in $\mathrm{CD}_{3} \mathrm{COCD}_{3}(0.5 \mathrm{ml})$ in an $\mathrm{NMR}$ tube and 20 mol equiv. of aniline, $\mathrm{MeCN}$, or $\mathrm{NH}_{4} \mathrm{OH}$ (as a 25 wt. \% in $\mathrm{H}_{2} \mathrm{O}$ ) were added. Compound 3 was dissolved in $\mathrm{CD}_{3} \mathrm{COCD}_{3}(0.5 \mathrm{ml})$ in an NMR tube and 20 mol equiv. of aniline, $\mathrm{H}_{2} \mathrm{O}$ or $\mathrm{MeCN}$ were added. Compound 4 was dissolved in $\mathrm{CD}_{3} \mathrm{COCD}_{3}(0.5 \mathrm{ml})$ in an NMR tube and 20 mol equiv. of $\mathrm{H}_{2} \mathrm{O}, \mathrm{MeCN}$, or $\mathrm{NH}_{4} \mathrm{OH}$ (as a 25 wt. \% in $\mathrm{H}_{2} \mathrm{O}$ ) were added. The samples were analyzed by ${ }^{1} \mathrm{H}$ NMR spectroscopy.

Typical procedure for catalytic runs. Benzyl alcohol $(40 \mu \mathrm{L}, 0.4 \mathrm{mmol})$ was added to a solution of 1,2-dichlorobenzene $(2 \mathrm{~mL})$ containing the catalyst $(8 \mu \mathrm{mol})$ and hexamethylbenzene $(0.07$ $\mu \mathrm{mol})$ as internal standard. The vial was sealed and heated to $150^{\circ} \mathrm{C}$. The reaction was monitored by transferring aliquots $(50 \mu \mathrm{L})$ of the reaction mixture to an NMR tube containing $\mathrm{CDCl}_{3}(0.5$ $\mathrm{mL}$ ) and subsequent ${ }^{1} \mathrm{H}$ NMR spectroscopic analysis. 
General procedure for sequential additions of substrate. A mixture of complex $\mathbf{3}$ (16 mg, 0.02 $\mathrm{mmol}), 1,2$-dichloromethane $(2 \mathrm{~mL})$ and benzyl alcohol $(41 \mu \mathrm{L}, 0.4 \mathrm{mmol})$ was heated for 20 hours at $150{ }^{\circ} \mathrm{C}$. An aliquot was taken for determining the conversion as detailed above, and a fresh portion of benzyl alcohol was added. This procedure was repeated in intervals of $24 \mathrm{~h}$.

\section{Crystal structure determinations.}

Crystal data for $\mathbf{3}$ and $\mathbf{4}$ were collected using a Rigaku (former Agilent Technologies) Oxford Diffraction SuperNova A diffractometer fitted with an Atlas detector and using monochromated Mo- $\mathrm{K}_{\alpha}$ radiation $(0.71073 \AA)$. A complete dataset was collected, assuming that the Friedel pairs are not equivalent. The structures were solved by direct methods using SHELXS-97 and refined by full-matrix least squares fitting on $\mathrm{F}^{2}$ for all data using SHELXL-97. ${ }^{20}$ Hydrogen atoms were added at calculated positions and refined by using a riding model. Anisotropic thermal displacement parameters were used for all non-disordered nonhydrogen atoms. Further crystallographic details are compiled in Tables S3 and S4. Crystallographic data (excluding structure factors) for both complexes have been deposited with the Cambridge Crystallographic Data Centre as supplementary publication no. CCDC 1583136 (3) and 1583137 (4).

\section{ASSOCIATED CONTENT}

Supporting Information: NMR spectra and crystallographic details of new complexes 3 and 4. Catalytic results.

\section{AUTHOR INFORMATION}

Corresponding Author: *E-mail: martin.albrecht@dcb.unibe.ch

Notes: The authors declare no competing financial interest.

\section{ACKNOWLEDGEMENTS}

We acknowledge generous financial support from the European Research Council (CoG 615653) and from the Swiss National Science Foundation (200021_162868, R'equip projects 206021_128724 and 206021_170755).

\section{REFERENCES}


1. a) R. H. Crabtree, Chem. Rev. 2017, 117, 9228-9246; b) M. Nielsen, Hydrogen Production by Homogeneous Catalysis: Alcohol Acceptorless Dehydrogenation. In Hydrogen Production and Remediation of Carbon and Pollutants, eds. E. Lichtfouse, J. Schwarzbauer and D. Robert, Springer, Heidelberg, 2015; c) Modern Oxidation Methods, ed. J.-E. Bäckvall, Wiley-VCH, Weinheim, Germany, 2008; d) The Handbook of Homogeneous Hydrogenation, eds. J. G. De Vries and C. J. Elsevier, Wiley-VCH, Weinheim, Germany, 2008.

2. For selected reviews on NHCs: a) D. Bourissou, O. Guerret, F. P. Gabbai and G. Bertrand, Chem. Rev. 2000, 100, 39-92; b) A. J. Arduengo and G. Bertrand, Chem. Rev. 2009, 109, 3209-3210 (thematic issue); c) L. Mercs and M. Albrecht, Chem. Soc. Rev. 2010, 39, 1903-1912; d) M. Melaimi, M. Soleilhavoup and G. Bertrand, Angew. Chem. Int. Ed. 2010, 49, 8810-8849; e) NHeterocyclic Carbenes: from Laboratory Curiosities to Efficient Synthetic Tools (2 ${ }^{\text {nd }}$ Edition), ed. S. Díez-González, RSC Publishing, Cambridge, 2017; f) H. V. Huynh, The Organometallic Chemistry of N-heterocyclic Carbenes, Wiley, Chichester, 2017.

3. a) W. A. Herrmann, Angew. Chem. Int. Ed. 2002, 41, 1290-1309; b) C. M. Crudden and D. P. Allen, Coord. Chem. Rev. 2004, 248, 2247-2273; c) E. Peris and R. H. Crabtree, Coord. Chem. Rev. 2004, 248, 2239-2246 (d) F. E. Hahn and M. C. Jahnke, Angew. Chem. Int. Ed. 2008, 47, 3122-3172; e) H. Jacobsen, A. Correa, A. Poater, C. Costabilie and L. Cavallo, Coord. Chem. Rev. 2009, 253, 687-703; f) S. Díez-González, N. Marion and S. P. Nolan, Chem. Rev. 2009, 109, 3612-3676; g) E. Peris, Chem. Rev. 2017, in press (DOI: 10.1021/acs.chemrev.6b00695); h) NHeterocyclic Carbenes in Transition Metal Catalysis and Organocatalysis, ed. C. S. J. Cazin, Springer, Berlin, 2011; i) N-Heterocyclic Carbenes in Transition Metal Catalysis, in Topics in Organometallic Chemistry, ed. F. Glorius, Springer, Berlin, 2007.

4. a) D. G. H. Hetterscheid and J. N. H. Reek, Chem. Commun. 2011, 47, 2712-2714; b) R. H. Crabtree, J. Organomet. Chem. 2014, 751, 174-180; c) J. A. Woods, R. Lalrempuia, A. Petronilho, N. D. McDaniel, H. Müller-Bunz, M. Albrecht and S. Bernhard, Energy Environ. Sci. 2014, 7, 2316-2328; d) A. Petronilho, J. A. Woods, H. Müller-Bunz, S. Bernhard and M. Albrecht, Chem. Eur. J. 2014, 20, 15775-15784; e) P. Daw, R. Petakamsetty, A. Sarbajna, S. Laha, R. Ramapanicker and J. K. Bera, J. Am. Chem. Soc. 2014, 136, 13987-13990.

5. For selected examples see: a) A. Prades, E. Peris and M. Albrecht, Organometallics 2011, 30, 1162-1167; b) A. Bartoszewicz, R. Marcos, S. Sahoo, A. K. Inge, X. Zou and B. Martin-Matute, Chem. Eur. J. 2012, 18, 14510-14519; c) J. Campos, L. S. Sharninghausen, M. G. Manas and R. H. Crabtree, Inorg. Chem. 2015, 54, 5079-5084; d) V. Jimenez, J. Fernandez-Tornos, F. J. Modrego, J. J. Perez-Torrente and L. A. Oro, Chem. Eur. J. 2015, 21, 17877-17889; e) H. Horvath, G. Papp, R. Szabolcsi, A. Katho and F. Joo, ChemSusChem 2015, 8, 3036-3038.

6. a) D. Canseco-González and M. Albrecht, Dalton Trans. 2013, 42, 7424-7432; b) M. DelgadoRebollo, D. Canseco-Gonzalez, M. Hollering, H. Müller-Bunz and M. Albrecht, Dalton Trans. 2014, 43, 4462-4473; c) S. Hohloch, S. Hettmanczyk and B. Sarkar, Eur. J. Inorg. Chem. 2014, 3164-3171; d) A. Bolje, S. Hohloch, D. Urankar, A. Pevec, M. Gazvoda, B. Sarkar and J. Kosmrlj, Organometallics 2014, 33, 2588-2598; e) K. F. Donnelly, C. Segarra, L.-X. Shao, R. Suen, H. Müller-Bunz and M. Albrecht, Organometallics 2015, 34, 4076-4084; f) S. Sabater, H. Müller- 
Bunz and M. Albrecht, Organometallics 2016, 35, 2256-2266; g) R. Pretorius, J. Olguín and M. Albrecht, Inorg. Chem. 2017, 56, 12410-12420.

7. a) B. Bagh, A. M. McKinty, A. J. Lough and D. W. Stephan, Dalton Trans. 2014, 43, $12842-$ 12850; b) M. Valencia, A. Pereira, H. Müller-Bunz, T. R. Belderraín, P. Pérez and M. Albrecht, Chem. Eur. J. 2017, 23, 8901-8911.

8. a) A. Prades, R. Corberán, M. Poyatos and E. Peris, Chem. Eur. J. 2008, 14, 11474-11479.b) M. Valencia, H. Müller-Bunz, R. A. Gossage and M. Albrecht, Chem. Commun. J. 2016, 52, 33443377.

9. A. Petronilho, A. Vivancos and M. Albrecht, Catal. Sci. Technol. 2017, in press (10.1039/C7CY01832K).

10. A. Petronilho, A. Llobet and M. Albrecht, Inorg. Chem. 2014, 53, 12896-12901.

11. R. P. Hughes, J. M. Smith, C. D. Incarvito, K.-C. Lam, B. Rhatigan, A. L. Rheingold, Organometallics 2002, 21, 2136-2144.

12. M. P. Betore, P. Garcia-Orduna, F. J. Lahoz, M. A. Casado, V. Polo and L. A. Oro, Eur. J. Inorg. Chem. 2016, 5347-5355; The resonance is also at lower field than iridium(III) phosphine ammonia complexes, see for example: M. A. Salomon, A.-K. Jungton and T Braun, Dalton Trans. 2009, 7669-7677.

13. K. F. Donnelly, A. Petronilho and M. Albrecht, Chem. Commun. 2013, 49, 1145-1159.

14. V. Leigh, W. Ghattas, R. Lalrempuia, H. Müller-Bunz, M. T. Pryce and M. Albrecht, M. Inorg . Chem. 2013, 52, 5395-5402.

15. $(\mathrm{Ir}-\mathrm{C} 1+3 \sigma=2.008$ and $\mathrm{Ir}-\mathrm{C} 1 \mathrm{~b}+3 \sigma=2.015)$.

16. (a) P. Mathew, A. Neels and M. Albrecht, J. Am. Chem. Soc. 2008, 130, 13534-13535; b) G. Guisado-Barrios, J. Bouff ard, B. Donnadieu and G. Bertrand, Angew. Chem. Int. Ed. 2010, 49, 4759-4762; c) J. D. Crowley, A.-L. Lee and K. J. Kilpin, Aust. J. Chem. 2011, 64, 1118-1132.

17. (a) R. Lalrempuia, N. D. McDaniel, H. Müller-Bunz, S. Bernhard and M. Albrecht, Angew. Chem. Int. Ed. 2010, 49, 9765-9768; b) I. Corbucci, A. Petronilho, H. Müller-Bunz, L. Rocchigiani, M. Albrecht and A. Macchioni, ACS Catal. 2015, 5, 2714-2718.

18. (a) K. Riener, M. P. Höger, P. Gigler, F. E. Kühn, ACS Catal. 2012, 2, 613-621; b) P. Gigler, B. Bechlars, W. A. Herrmann, F. E. Kühn, J. Am. Chem. Soc. 2011, 133, 1589-1596.

19. The selectivity of the fifth batch is less clear due to the substantial catalyst deactivation.

20. G. M. Sheldrick, Acta Crystallogr. Sect. A, 2008, 64, 112. 